\title{
Description of a Specimen of Allantoidoangiopagous Twins.
}

\author{
By Daniel Dougal, M.D.,
}

Hon. Assistant Surgeon, Manchester Northern Hospital; Pathologist, St. Mary's Hospitals.

Allantordo-angiopagous twins are uniovular fœetuses which communicate with one another by means of the vessels of their umbilical cords near to or within the single placenta. As a rule, one of them is fairly normal in appearance, but in the other the deformity is generally of an extreme type. The foetuses are always of the samp sex, and have sometimes been called placental parasites, but Ballantyne ${ }^{1}$ considers this to be a misnomer, as one twin is really a parasite on the other and not on the placenta.

There are three chief groups of this type of monstrosity, the paracephalic, the acephalic, and the amorphous respectively.

The paracephalic type is distinguished by the presence of a head, the other parts of the body showing varying degrees of deformity.

In the acephalic monster there is, of course, no head, whilst the amorphous form lacks the external appearances of a fotus, and may consist of little more than an oval skin-covered mass.

The specimens which I have dissected, and which form the subject of this communication, present many interesting features, the larger twin being anencephalic, whilst the former one belongs to the amorphous group already mentioned.

The larger foetus measures twelve inches in length and weighs 22 ounces. It is of the female sex, and presents the typical appearances of an anencephalic monster.

The umbilical cord measures seven inches in length and contains two vessels, there being only one umbilical artery present.

This is an interesting abnormality in itself, and on making a dissection it is found that this single artery is a continuation of the abdominal aorta, and gives off within the abdomen the right common iliac artery and close to its point of entrance into the cord, the superior vesical artery.

The common iliac on the left side arises directly from the aorta, and much higher up.

The internal organs of this foetus are of normal appearance with the exception of the heart, which is somewhat hypertrophied, due, no doubt, to the increased work thrown upon it by the parasitic twin.

The smaller fotus resembles a kidney in appearance, and has a portion of umbilical cord attached to it very much in the same position as the ureter in the case of that organ. 
Plate I.

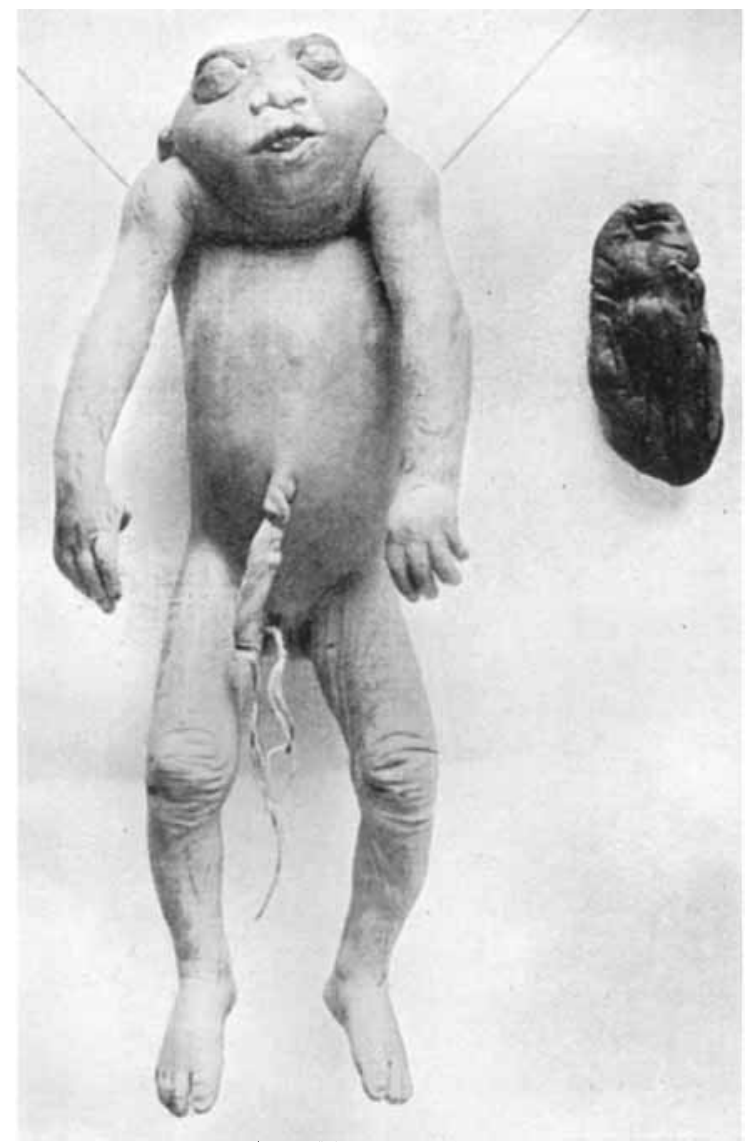

Showing relative size of 'Twins.

a. Larger, anencephalic foetus.

b. Smaller, amorphous fotus. 
Plate II.

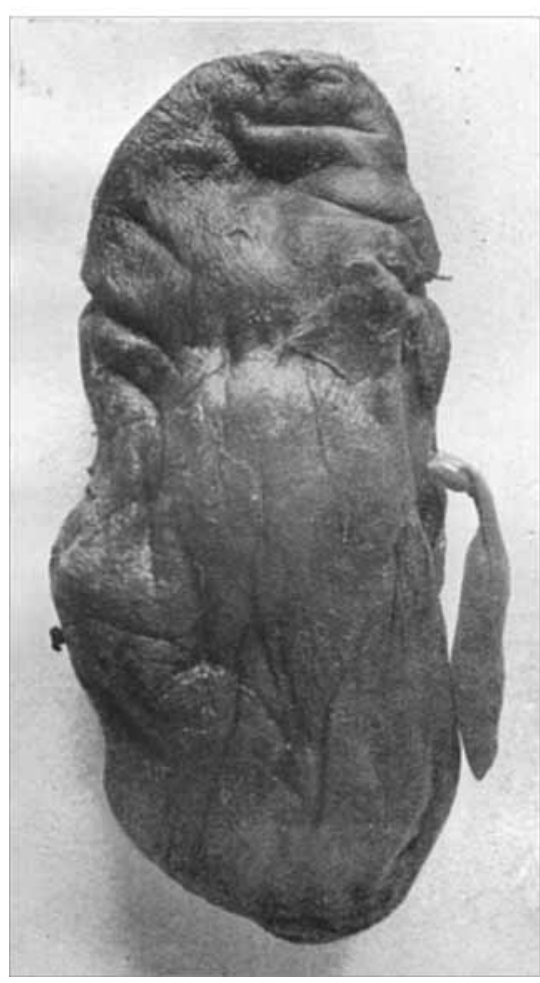

A

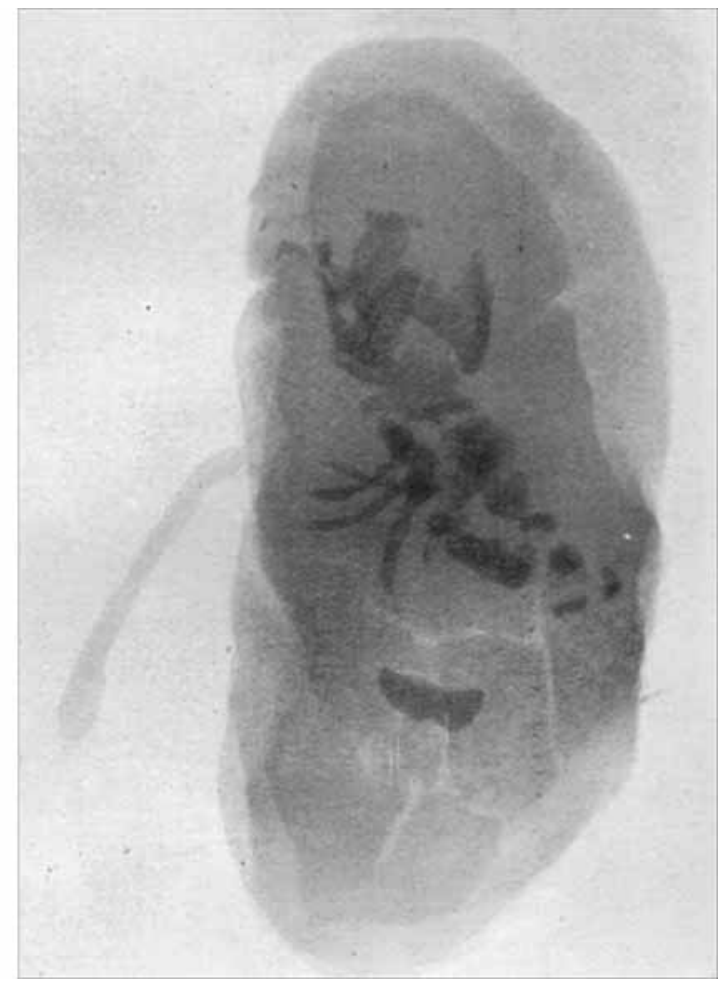

B

The Amorphors Fotus.

b. Ratiogram of Lateral aspect. 
Plate II. (continued).

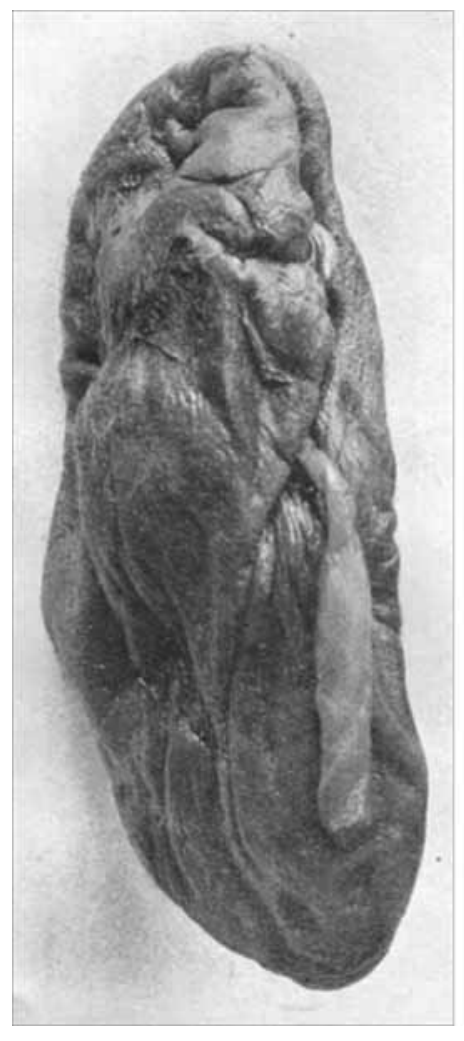

C

c. Antero-posterior aspect.

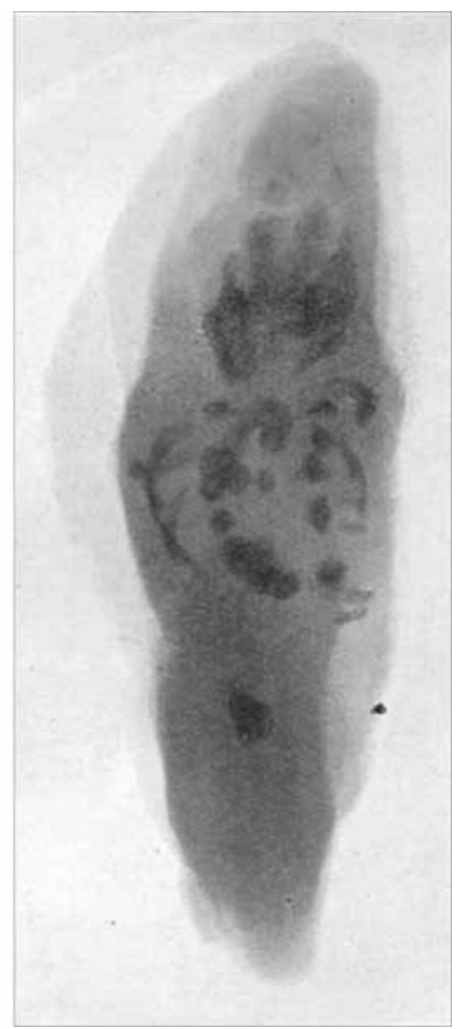

D)

d. Radiogram of antero-posterior aspect. 
It measures $3 \frac{1}{2}$ inches in length, $1 \frac{3}{4}$ inches antero-posteriorly, and 1 inch laterally, and weighs about an ounce and a half.

There are no sexual characteristies present, but the sex is presumably the same as that of the other twin.

External Appearances.-The surface of the foetus is of a deep brownish-red colour, and thrown into numerous wrinkles.

Fine hairs are present over the whole surface, but are more numerous near the upper end over the part corresponding to the scalp.

There is no trace externally of limbs or limb buds.

Near the upper end of the fotus and on its anterior surface are four fleshy processes enclosing a deep fissure. These represent the fronto-nasal, maxillary, and mandibular processes, and surround the imperfectly-formed mouth of the foetus.

About the same level and on each lateral surface is a small pit, which may represent the external auditory meatus.

Hard, irregular masses are felt through the skin, and a radiogram of the foetus shows these to consist of masses of cartilage enclosing smaller areas of bone formation.

Osseous System.-A study of the radiogram and of a mesial section of the foetus shows that the bones of the skull and vertebral column are fairly well developed, and enclose a large cavity containing the central nervous system.

Within the fronto-nasal process the cartilage is hollowed out into numerous cavities, which evidently represent the fronto-ethmoidal cells.

At least four ribs can be made out on each side and behind, and on the outer surface of these several small, irregular portions of bone probably correspond to an incompletely-developed shoulder girdle.

The lower end of the vertebral column is bent forwards to form an angle of about $80^{\circ}$ with the upper part, and is composed entirely of cartilage.

The pelvic bones are represented by a bony-cartilaginous mass, which is found on section to be composed of four separate pieces. In only one of these has ossification taken place, and this probably represents the ilium, the centre for which appears about the end of the second month of intra-uterine life.

The other internal structures of the fœtus were studied in a mesial section.

Opposite to the entrance of the vessels of the umbilical cord is a large cavity evidently forming the coelom, and containing a single organ, the heart.

There are no abdominal organs to be found.

Two vessels enter from the cord, the vein running up to the heart, the artery coursing downwards in association with a structure representing the allantois, and immediately behind the mass of cartilage lying at the pelvic end of the fœetus. 
It was impossible to make a complete dissection of the vascular system, but a comparatively large vessel was found running upwards in front of the vertebral column, and evidently forming a primitive aorta.

The heart is a fairly large organ, with rather thin walls, and containing a single chamber, lying within the coelom, the diaphragm being totally undeveloped. Immediately above the heart is the cavity of the pharynx, whilst behind the vertebral column is in close apposition with it. The circulation, such as it is, probably consists of a simple vascular circle connected with the heart, but the latter organ has evidently had little functional value, to judge from its thin-walled and dilated appearances, and the stronger heart of the other twin evidently overpowered it and usurped its functions.

The central nervous system is present, the spinal cord being especially well-developed, but the faulty preservation of this tissue prevented any detailed examination being made.

The common placenta measures $6 \frac{1}{2}$ inches in diameter and weighs 12 ounces.

The cord of the larger fotus has a velamentous insertion, and shortly after joining the placenta proper the umbilical artery and vein each give off a small branch, and these, coming together, course outwards on the surface of the chorion in similar fashion to the vessels which supply a succenturiate placenta.

There is no doubt that these vessels represent the vascular attachment of the parasitic fotus, which, therefore, does not get a supply of freshly-oxygenated blood, but only obtains it second hand from its more powerful partner.

Opinion differs widely as to the origin and mode of development of this type of monstrosity. The most probable explanation is that one fœtus obtains a larger share of or an earlier attachment to the chorionic vessels, and as a result starves out its less fortunate companion.

The latter, if left to its own resources, would probably die, but it appears as if the other twin, having gravely interfered with the nutrition of its fellow, now proceeds to carry on the latter's circulation in a reverse direction and with imperfectly oxygenated blood, with the result that growth continues, but along abnormal lines.

A second view holds that the larger fotus plays a beneficent role from the very beginning, and that the development of the smaller one is so imperfect that ante-natal existence would be absolutely impossible but for the help received from the other's circulatory system.

For the specimens above described I am indebted to Dr. W. K. Walls, to whom they were sent by Dr. Moir, of Darwen.

\section{REFERENCE.}

(1) Ballantyne, J. W., Manual of Antenatal Pathology and Hygiene. Vol. 1. The Embryo. p. 623. 


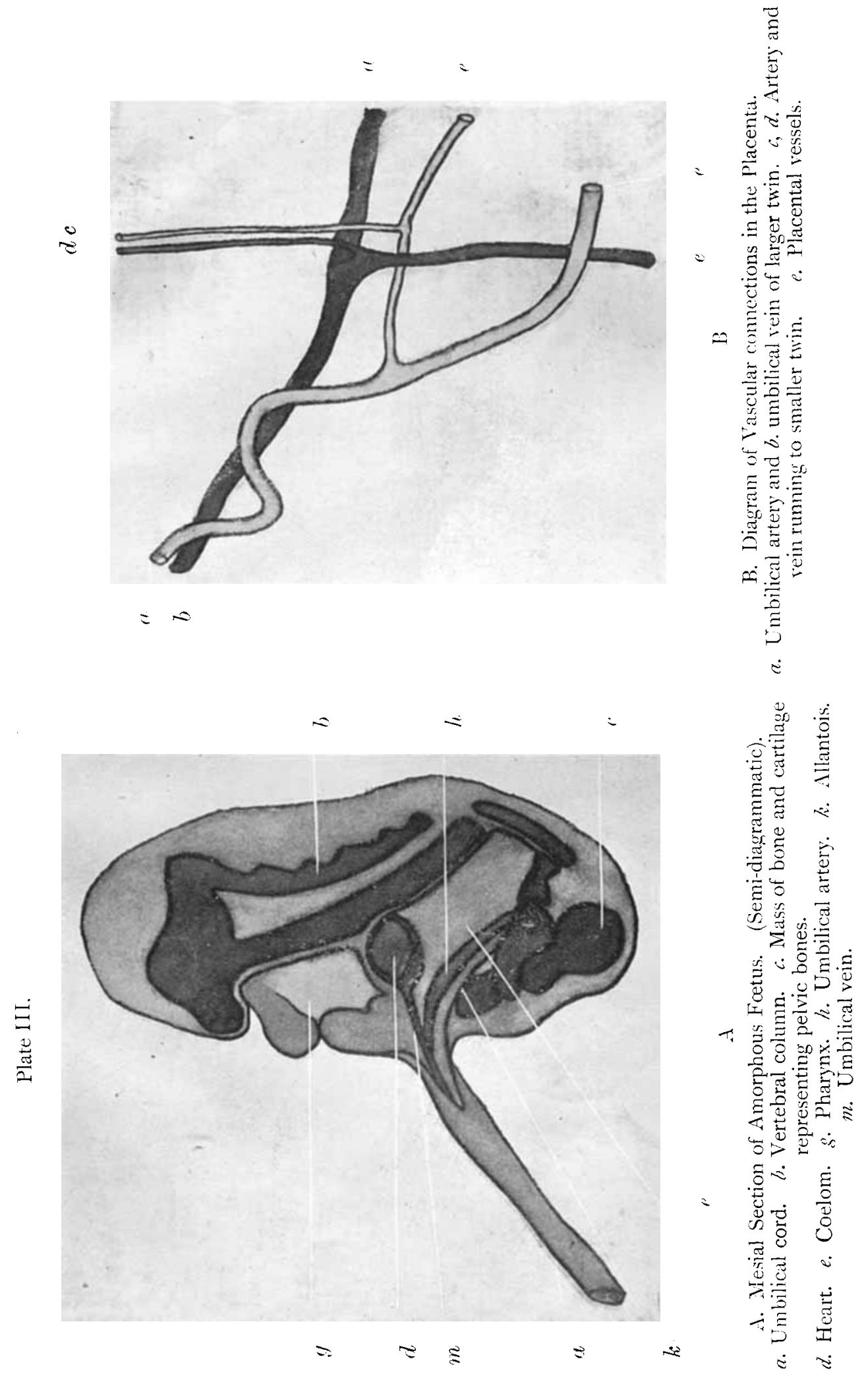


Plate III. (continued).

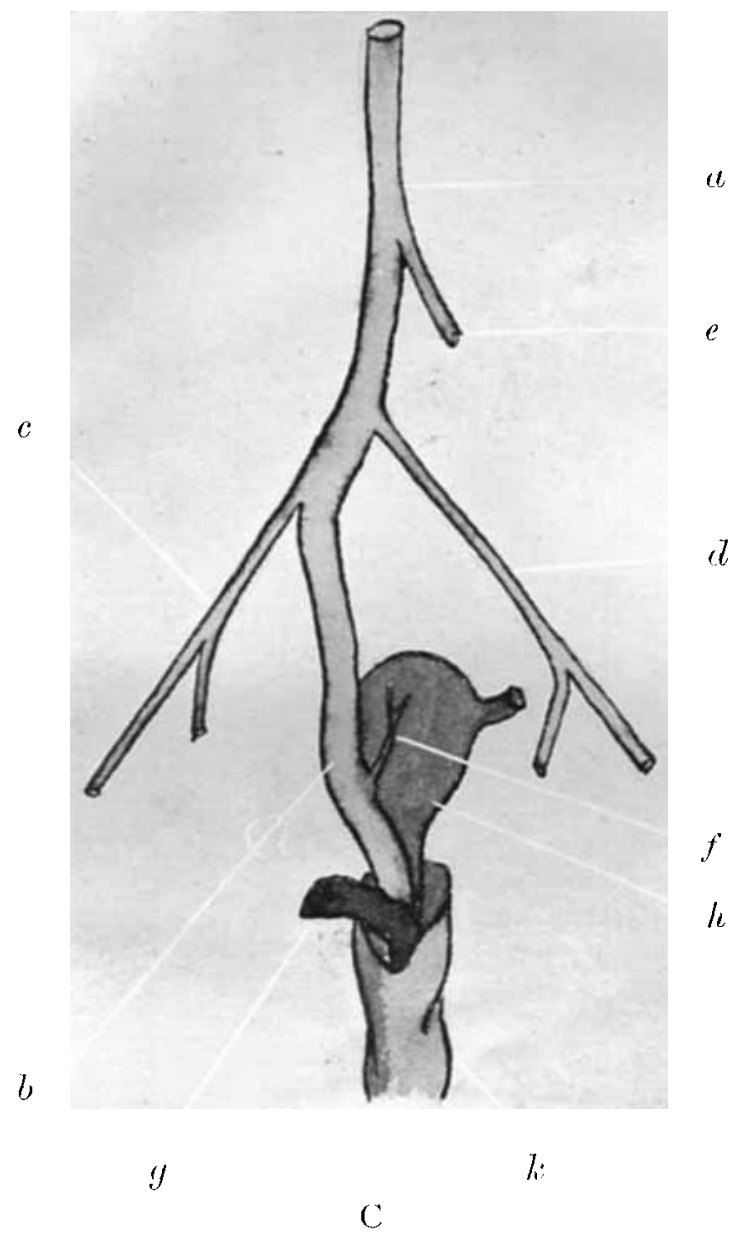

C. I halgram of Single Umbilical Artery in larger twin.

a. Abdominal aorta. b. Umbilical artery. c. Right common iliac artery. d. Left common iliac artery. e. Inferior mesenteric artery. $f$. Superior vesical artery. g. Umbilical vein. h. Bladder. $k$. Umbilical cord. 